\title{
Bone mineral density, milk intake and physical activity in boys who suffered forearm fractures
}

\author{
Luiz Antônio Simões Pires, ${ }^{1}$ Antônio Carlos Araújo de Souza, ${ }^{2}$ \\ Orlando Laitano, ${ }^{3}$ Flávia Meyer ${ }^{4}$
}

\begin{abstract}
Objective: To compare boys with and without forearm fracture in terms of their bone mineral density, intake of milk and dairy products, and physical activity.

Methods: There were 23 boys in each group (aged between 7 and 13 years). They were submitted to bone densitometry with dual-energy $\mathrm{x}$-ray absorptiometry (DEXA) of the forearm (opposite side of the fracture). Participants answered questionnaires about their intake of milk and dairy products, and about their physical activity.

Results: The mean \pm SD of the bone mineral density of the radial and ulnar distal diaphysis in the case group $\left(0.430 \pm 0.038 \mathrm{~g} \cdot \mathrm{cm}^{-2}\right)$ was significantly lower $(p=0.018)$ than that of the control group $\left(0.458 \pm 0.039 \mathrm{~g} \cdot \mathrm{cm}^{-2}\right)$. Likewise, the mean of the distal metaphysis of the forearm was $0.309 \pm 0.033 \mathrm{~g} \cdot \mathrm{cm}^{-2}$ in the case group and $0.349 \pm 0.054 \mathrm{~g} \cdot \mathrm{cm}^{-2}$ in the control group $(p=0.004)$. Milk intake $(1.5 \pm 1.2$ cups a day) was significantly lower in the case group $(p=0.001)$ than in the control group ( $2.7 \pm 1.2$ cups a day). The number of boys who practiced after-school physical activity was significantly lower $(p=0.017)$ in the case group ( six boys $=26 \%)$ than in the control group $(15$ boys $=53 \%$ ).
\end{abstract}

Conclusion: Boys who suffered forearm fracture showed lower bone mineral density compared with the control group. In the case group, milk intake and physical activity were lower than in the control group.

J Pediatr (Rio J). 2005;81(4):332-6: Bone health, calcium intake, childhood.

\section{Introduction}

Bone fractures are a concern as they cause morbidity and sequelae that can affect mainly the joints. Fractures can occur at any stage of life, and are more common among children. The intensity and the mechanisms of injury, as well as bone resistance to fracture, are factors that determine the probability of a fracture. The intensity of the trauma is an important determining factor for fracture, but bone mineral density (BMD), upon which resistance to fracture depends, ${ }^{1}$ also plays a role.

1. MSc, Universidade Federal do Rio Grande do Sul (UFRGS), Porto Alegre, RS, Brazil.

2. PhD, University of Tokyo.

3. Specialist in Health Sciences, Pontifícia Universidade Católica do Rio Grande do Sul (PUCRS), Porto Alegre, RS, Brazil.

4. PhD, McMaster University.

Manuscript received Sep 10 2004, accepted for publicationApr 132005.

Suggested citation: Pires LA, de Souza AC, Laitano O, Meyer F. Bone mineral density, milk intake and physical activity in boys who suffered forearm fractures. J Pediatr (Rio J). 2005;81:332-6.
Few studies on bone resistance and BMD and on the possibility of low BMD in the event of a fracture have included pediatric patients. Marhaug ${ }^{2}$ suggested that the bones of children who suffered a fracture have a low bone mineral content (BMC) compared to a control group (with no fractures).

Peak calcium $\left(\mathrm{Ca}^{++}\right)$requirements occur during childhood and adolescence, a crucial period for maximization of bone density. ${ }^{3}$ According to Fuchs \& Snow, ${ }^{4}$ the low intake of $\mathrm{Ca}^{++}$in childhood is related to an increased risk of fractures at this developmental stage; however, the interplay between $\mathrm{Ca}^{++}$intake and exercise during childhood is underreported in the literature.

Distal forearm fractures account for $21 \%$ of all fractures that occur in individuals younger than 17 years. ${ }^{5}$ Several in vitro and in vivo studies have been conducted since the 1980 s in an attempt to establish an association between BMD and bone resistance to fracture. ${ }^{1,5-7}$

The incidence of forearm fractures reaches its peak at the age of 13 , affecting 807 and 140 per 100,000 boys and 
girls, respectively. ${ }^{8}$ This period precedes the critical years for bone mass accumulation, which is evident at the age of 14-15 years. ${ }^{9}$ The radius is the most commonly fractured long bone among children, representing $45 \%$ of the fractures. ${ }^{10}$ Hagino et al. ${ }^{8}$ studied Japanese individuals aged less than 20 years and suggested that low bone density of the distal diaphysis of the forearm may be the cause for a higher incidence of fractures at this site.

Families often wonder whether their children have weak bones, especially when the trauma that caused the fracture was not so strong. The answer to this question is not straight, once thorough examination is necessary after ruling out the possibility of inherited or acquired diseases.

The most referenced studies seeking to establish an association between bone mass and fracture in children 8,11 have shown that lower bone mass may increase the risk of fractures in children. Goulding et al. ${ }^{12}$ noted that a low BMC and lack of physical activity are associated with the enhanced risk of distal forearm fractures in boys.

The aim of the present study was to compare boys with and without forearm fractures in terms of their BMD, daily intake of dairy products, and physical activity.

\section{Methods}

Case-control study in which forearm fracture was measured as an outcome and BMD was the analyzed factor.

\section{Subjects}

Both age and gender of the analyzed group were based on the studies ${ }^{13-15}$ that found some evidence of regular and progressive bone mass accumulation in male individuals up to the age of 15 or 18 years, differently from female subjects, in whom there is sudden bone mass acquisition after the menarche. The boys who volunteered to participate in the study were all Caucasian and aged between 7 and 13 years. The case group was comprised of boys who fractured the diaphysis/metaphysis of the forearm (submitted to treatment) involving at least the radius. Participants were recruited from the Orthopedic Outpatient Clinic of Hospital São Lucas da Pontifícia Universidade Católica do Rio Grande do Sul (HSL-PUCRS), in Porto Alegre, southern Brazil. Surrogates signed a consent form, and the local Research Ethics Committee approved the study protocol.

The inclusion criteria in the case group were the following: medical treatment for less than 12 months, no orthopedic deformities, fractures involving the radius, with or without ulnar involvement, closed fracture (complete or incomplete), low-trauma fracture, i.e., by falling from a standing height or less while doing habitual activities (e.g.: during sports activities) and not related to traffic accidents. Initial x-ray was evaluated on admission to HSL-PUCRS.

The control group included boys who sought medical care at the Orthopedic Outpatient Clinic, with no past or current history of fracture, with no clinically relevant osteoarticular disorders, and without any orthopedic deformities. Therefore, they were not submitted to any kind of rest over the last months. The most frequent reasons for having sought medical care were muscle contusion and clinical examination upon the request of parents to check the existence of pes planus and spinal deformities.

\section{Procedures}

Participants completed a questionnaire about their intake of milk and other dairy products and another questionnaire about physical activity in which school and after-school activities were described. ${ }^{16}$ On that occasion, weight and height were measured (Filizola), and information about the participants' state of health and occurrence of fractures was collected.

Bone densitometry (BD) was performed within two weeks after the initial evaluation at the Division of Densitometry of the Institute of Geriatrics (HSL-PUCRS) in Porto Alegre, using a Hologic QDR-4500 Acclaim fan-beam scanner (Boston-USA). The equipment was calibrated on a daily basis, following the routine of the Division of Densitometry.

Forearm scans were performed. Patients in the case group had their unfractured forearm evaluated, and in the control group, the scanned forearm was that which matched its counterpart in the case group.

\section{Statistical analysis}

Mean and standard deviation were calculated in the case of quantitative variables, whereas for categorical variables, absolute frequency and percentage were used. The case and control groups were compared by Student's t test for independent samples in the case of quantitative variables. The chi-square test with Yates' correction in $2 \times 2$ tables and Fisher's exact test (whenever necessary) were used for the categorical variables. The significance level was established at $\alpha \leq 0.05$.

We used the mean difference observed between groups as an estimator of the magnitude of the analyzed associations. ${ }^{16-18}$ The data were analyzed by Excel 97, SPSS v.9.0 and PEPI v.3.0 programs.

\section{Results}

Case and control groups were similar in terms of age, weight, height, and body mass index (BMI).

\section{Intake of milk and other dairy products}

Milk intake was lower in the case group than in the control group (Table 1). On average, individuals in the control group had the habit of drinking 1.2 more glasses of milk than those in the case group. This is a moderate and statistically significant difference $(p=0.001)$. With regard to the consumption of yogurt and cheese, no statistically significant difference was observed between the groups in this study. 
Table 1 - Milk, yogurt and cheese consumption in each group

$\begin{array}{cccc}\text { Case } & \text { Control } & \text { Mean } & p \\ (n=23) & (n=23) & \text { difference } & \end{array}$

\begin{tabular}{lcccc}
\hline $\begin{array}{l}\text { Number of glasses } \\
\text { of milk/day }\end{array}$ & $1.5 \pm 1.2$ & $2.7 \pm 1.2$ & 1.2 & 0.001 \\
$\begin{array}{l}\text { Number of yogurt } \\
\text { pots/day }\end{array}$ & $0.7 \pm 0.6$ & $0.8 \pm 0.7$ & 0.1 & 0.596 \\
$\begin{array}{l}\text { Number of slices of } \\
\text { cheese/week }\end{array}$ & $1.0 \pm 1.2$ & $1.1 \pm 0.8$ & 0.1 & 0.208
\end{tabular}

Data are presented in mean $\pm S D$.

\section{Physical activity}

As shown in Table 2, the number of children who engaged in regular after-school activities corresponded to nearly $65 \%$ in the control group, and to only $26 \%$ in the case group. This $39 \%$ difference was statistically significant $(p=0.017)$. No significant difference was found between the groups with regard to leisure activities and to the active participation of students in activities during their breaktime at school.

\section{Forearm BMD}

Table 3 shows the BMD of case and control groups stratified by different regions of the forearm. The groups revealed a moderate difference in the BMD of the distal metaphysis (mean difference $=0.04 ; p=0.004$ ). We also found significant difference, with the same magnitude, in the BMD of the distal diaphysis (mean difference $=0.028$; $p=0.018$ ). As to the medial third of the forearm, BMD was similar in both groups.

As far as total BMD of the forearm is concerned, we observed significant difference between the groups, with moderate intensity, showing statistical significance (mean difference $=0.031 ; p=0.004)$.

\section{Discussion}

The forearm considered for BMD in the control group was case-matched, following the order of inclusion in the study, and matched by dominance (right or left). This was done because, according to Karjalainen \& Alhava, ${ }^{19}$ BMC may be 6 to $9 \%$ higher in the radius, on the dominant side. In general, the values obtained by similar studies showed that BMD is accountable for bone resistance in approximately 70 to $80 \% .20,21$ Whether the boys from the case group were not capable of using the unaffected upper limb was not evaluated in a systematic fashion in this study. Therefore, we do not know whether this factor interfered with the results.

Due to racial differences in BMD, ${ }^{22-24}$ only Caucasian boys participated in the study. Exposure to sunlight, which is essential for vitamin D synthesis, was not evaluated in this study. We believe it was similar in both groups, since cases and controls were assessed at the same time of the year.

We added the intensity of the trauma that caused the fracture to the selection criteria of the case group. Fractures resulted from falls (low-trauma fractures). According to Landin \& Nilsson, ${ }^{5}$ this is an important aspect to be considered, since forearm fractures in children as a result of low trauma may indicate a lower BMC in this region.

The present study revealed a significantly lower BMD in forearm regions that were more prone to fractures. These data are clinically relevant, since studies on fractures have demonstrated that the risk of fracture doubles with every standard deviation below the mean. ${ }^{12}$

With regard to nutritional aspects, the 24-hour diet recall was not used; instead, we used a questionnaire about the intake of milk and other dairy products (main sources of calcium). Nevertheless, this method did not allow estimating whether children had achieved the age-appropriate calcium intake (1,300 mg/day). ${ }^{25}$ This study showed that children who suffered fractures have a lower milk intake. These data concur with those of Chan et al. ${ }^{11}$ whose study of children younger than 12 years who had suffered a forearm fracture revealed that four out of 17 children met less than $60 \%$ of the recommended calcium intake (minimum of $240 \mathrm{ml}$ of milk a day, in addition to other dietary sources), and that in the control group, all children met at least the minimum recommended intake. Therefore, as shown by several studies, $3,4,26-30$ there is a positive association between calcium intake and bone mass accumulation in children.

Table 2 - Number of boys engaged in physical activity in each group

\begin{tabular}{lccccccc}
\hline & \multicolumn{2}{c}{ Case $(\mathbf{n}=\mathbf{2 3})$} & & \multicolumn{2}{c}{ Control $(\mathbf{n}=\mathbf{2 3})$} & p \\
\cline { 2 - 3 } & $\mathbf{f}$ & $\mathbf{\%}$ & & $\mathbf{f}$ & $\mathbf{\%}$ & \\
\hline Leisure activities & 22 & 95.7 & & 23 & 100.0 & 0.999 \\
During breaktime at school & 19 & 82.6 & & 20 & 87.0 & 0.999 \\
After-school activities & 6 & 26.1 & & 15 & 65.2 & & 0.017 \\
\hline
\end{tabular}


Table 3 - Bone mineral density according to forearm region in $\mathrm{g} \cdot \mathrm{cm}^{-2}$

\begin{tabular}{lcccc}
\hline & $\begin{array}{c}\text { Case } \\
(\mathbf{n = 2 3 )}\end{array}$ & $\begin{array}{c}\text { Control } \\
(\mathbf{n = 2 3})\end{array}$ & $\begin{array}{c}\text { Mean } \\
\text { difference }\end{array}$ & $\mathbf{p}$ \\
\hline Density of the medial third & $0.515 \pm 0.045$ & $0.534 \pm 0.060$ & 0.019 & 0.220 \\
Density of the distal diaphysis & $0.430 \pm 0.038$ & $0.458 \pm 0.039$ & 0.028 & 0.018 \\
Density of the distal metaphysis & $0.309 \pm 0.033$ & $0.349 \pm 0.054$ & 0.04 & 0.004 \\
Total density & $0.420 \pm 0.032$ & $0.451 \pm 0.038$ & 0.031 & 0.004 \\
\hline
\end{tabular}

Data presented in mean $\pm S D$. The mean difference between groups is provided, followed by $P$ obtained through the Student's t test for independent samples.

Gallo ${ }^{31}$ asserts that the best way to achieve an adequate calcium intake is by the ingestion of calcium-rich foods. In this case, milk is the best source, since it contains a high proportion of calcium, is natural, and is easily consumed by children and adolescents.

According to Chan et al., ${ }^{11}$ children with fractures and below-average BMD should have their diet carefully assessed and be counseled about adequate calcium intake if their diet is potentially deficient.

Johnston et al. ${ }^{27}$ state that children who ingest more calcium improve their bone mass acquisition, and that nutrition and activity contribute $20 \%$ or more to BMD.

Despite genetic contributions to BMD, environmental factors, including physical exercise, are especially important before puberty. ${ }^{30,32}$ In the present study, the number of boys who engaged in after-school physical activities was significantly smaller in the case group $(26 \%)$ than in the control group (53\%). In this study, after-school activities were those such as soccer, basketball and swimming practice done twice or three times a week. These findings suggest that physical exercise may have a positive effect on bone mass acquisition, being larger in those individuals who are regularly involved in some kind of physical activity.

In conclusion, boys with forearm fractures had a lower BMD at the fracture site compared to those boys who have never had a bone fracture. In the group with fractures, milk intake was lower and boys participated less in afterschool physical activities than boys who have never suffered a fracture.

\section{References}

1. Genant HK, Glüer C-C, Lotz JC. Gender differences in bone density, skeletal geometry, and fracture biomechanics. Radiology. 1994;190:636-40.

2. Marhaug G. Idiopathic juvenile osteoporosis [case report]. Scand J Reumatol. 1993;22:45-7.

3. Kallio AK, Nichols DL, Essery EV, DiMarco NM, Sanborn CF. Nutrition education and calcium intake in children. Med Sci Sports Exerc. 2003;35(5 Suppl 1):S327.
4. Fuchs RK, Snow CM. Short-term bone gains in children are similar regardless of calcium intake: results from a randomized controlled exercise intervention trial. Med Sci Sports Exerc. 2002;34(5 Suppl 1):S58.

5. Landin L, Nilsson BE. Bone mineral content in children with fractures. Clin Orthop. 1983;178:292-6.

6. Hui SL, Slemenda CW, Johnston Jr CC. Age and bone mass as predictors of fracture in a prospective study. J Clin Invest. 1988;81:1804-9.

7. Fässler AL, Bonjour JP. Osteoporosis as a pediatric problem. Pediatr Clin North Am. 1995;42:811-24.

8. Hagino $H$, Yamamoto K, Teshima R, Kishimoto H, Nakamura T. Fracture incidence and bone mineral density of the distal radius in Japanese children. Arch Orthop Trauma Surg. 1990;109:262-4.

9. Silva CC, Goldberg TB, Teixeira AS, Dalmas JC. Mineralização óssea em adolescentes do sexo masculino: anos críticos para a aquisição da massa óssea. J Pediatr (Rio J). 2004;80:461-7.

10. Beekman F, Sullivan JE. Some observations on fracture of long bones in children. Am J Surg. 1941;51:722-38.

11. Chan GM, Hess M, Hollis J, Book LS. Bone mineral status in childhood accidental fractures. Am J Dis Child. 1984;138:569-70.

12. Goulding A, Jones IE, Taylor RW, Williams SM, Manning PJ. Bone mineral density and body composition in boys with distal forearm fractures: a dual-energy $\mathrm{x}$-ray absorptiometry study. J Pediatr. 2001;139:473-5.

13. Bonjour JP, Theintz G, Buchs B, Slosman D, Rizzoli R. Critical years and stages of puberty for spinal and femoral bone mass accumulation during adolescence. J Clin Endocrinol Metab. 1991;73:55-63.

14. Gordon $\mathrm{CL}$, Halton JM, Atkinson SA, Webber CE. The contributions of growth and puberty to peak bone mass. Growth Dev Aging. 1991;55:257-62.

15. Theintz G, Buchs B, Rizzoli R, Slosman D, Clavien H, Sizonenko $\mathrm{PC}$, et al. Longitudinal monitoring of bone mass accumulation in healthy adolescents: evidence for a marked reduction after 16 years of age at the levels of lumbar spine and femoral neck female subjects. J Clin Endocrinol Metab. 1992;75:1060-5.

16. Bar-Or O. Pediatric sports medicine: for the practitioner: from physiologic principles to clinical applications. New York: SpringerVerlag, 1983. [Comprehensive manuals in pediatrics]

17. Altman DG. Practical statistics for medical research. London: Chapman and Hall; 1991.

18. Hopkins WG. A new view of statistics [on line] [cited in 2001 Jan 22]. Available at: URL: http://davidmlane.com/hyperstat/ contents.html

19. Karjalainen $P$, Alhava EM. Bone mineral content of the forearm in a healthy population. Acta Radiol Ther Phys Biol. 1977;16:199208.

20. Horsman A, Currey JD, Phil D. Estimation of mechanical properties of the distal radius from bone mineral content and cortical width. Clin Orthop. 1983;176:298-304.

21. Johnston Jr CC, Slemenda CW. Peak bone mass, bone loss and risk of fracture. Osteoporosis Int. 1994;4 Suppl 1:S43-5. 
22. Ott SM. Attainment of peak bone mass [editorial]. J Clin Endocrinol Metab. 1990;71:1082 A-C.

23. Gilsanz V, Roe TF, Mora S, Costin G, Goodman WG. Changes in vertebral bone density in black girls and white girls during childhood and puberty. N Engl J Med. 1991;325:1597-600.

24. McCormick DP, Ponder SW, Fawcett HD, Palmer JL. Spinal bone mineral density in 335 normal and obese children and adolescents: evidence for ethnic and sex differences. J Bone Miner Res. 1991;6:507-13.

25. Institute of Medicine (US). Dietary references intakes for calcium, phosphorus, magnesium, vitamin $D$ and fluoride. Washington (DC): National Academy Press; 1998.

26. Sandler RB, Slemenda CW, LaPorte RE, Cauley JA, Schramm MM, Barresi ML, et al. Postmenopausal bone density and milk consumption in childhood and adolescence. Am J Clin Nutr. 1985;42:270-4.

27. Johnston Jr CC, Miller JZ, Slemenda CW, Reister TK, Hui S, Christian JC, et al. Calcium supplementation and increases in bone mineral density in children. N Engl J Med. 1992;327:82-7.

28. Välimäki $M J$, Kärkkäinen $M$, Lamberg-Allardt $C$, Laitinen $K$, Alhava E, Heikkinen J, et al. Exercise, smoking, and calcium intake during adolescent and early adulthood as determinants of peak bone mass. BM]. 1994;309:230-5. [Cardiovascular Risk in Young Finns Study Group]

29. Stallings VA. Calcium and bone health in children: a review. Am J Ther. 1997;4:259-73.

30. Barr SI, McKay HA. Nutrition, exercise, and bone status in youth. Int J Sports Nutr. 1998;8:124-42.

31. Gallo AM. Building strong bones in childhood and adolescence: reducing the risk of fractures in later life. Pediatr Nurs. $1996 ; 22: 369-74,422$.

32. Krall EA, Dawson-Hughes $B$. Heritable and life-style determinants of bone mineral density. J Bone Miner Res. 1993:8:1-9.

Correspondence:

Flávia Meyer

LAPEX - Laboratório de Pesquisa do Exercício

Rua Felizardo, 750, Jardim Botânico

CEP 90690-200 - Porto Alegre, RS, Brazil

Tel.: +55 513316.5861 